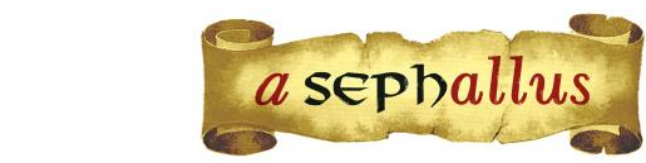

Revista aSEPHallus de Orientação Lacaniana Núcleo Sephora de Pesquisa sobre o Moderno e o Contemporâneo ISSN $1809-709$ X

\title{
Do porão ao facebook
}

Márcia Infante Vieira Psicanalista

Psicóloga pela Pontifícia Universidade Católica do Rio de Janeiro/PUC-RJ (Rio de Janeiro, Brasil) Mestranda do Programa de Pós-Graduação em Teoria Psicanalítica da Universidade Federal do Rio de Janeiro/UFRJ (Rio de Janeiro, Brasil)

E-mail: marciainfante@oi.com.br

Resumo: A apresentação dessa vinheta clínica visa evidenciar que estamos vivendo uma cultura da imagem, e avaliar o quanto podemos identificar seus efeitos na construção das subjetividades contemporâneas. Da sociedade disciplinar, lugar do sujeito do conflito, passamos à sociedade vigiada, lugar do sujeito narcisista, submetido ao imperativo do gozo. O capitalismo é analisado como causa da ruptura com a fé na história. Ruptura responsável por um colapso na cadeia explicativa que cercava o registro dos eventos públicos. 0 passado tornou-se irrelevante e o futuro vislumbrado como conturbado e incerto. O tempo é o aqui e o agora. O narcisista vive em um tempo suspenso e em litígio com a sociedade patriarcal. Surge no cenário um Outro liberal, que não proíbe, e sim, incita a gozar. (Por fim, o amor na direção do 'Dois' e não do 'Um' como saída). Palavras-chave: novas subjetividades; capitalismo; sujeito narcisista; imperativo do gozo.

\section{From the basement to facebook}

The presentation of this clinical vignette aims at reflecting how we are living a visible culture and how we can identify its effects on the construction of contemporary subjectivities. From the disciplinary society, place of the subject of the conflict, we move to the surveillance society, place of the narcissistic subject, submitted to the imperative of enjoyment. Capitalism is considered as the cause of the break with the faith in history. Break responsible for a collapse in the explanatory chain that surrounded the recording of public events. The past became irrelevant and the future glimpsed as troubled and uncertain. Time is here and now. The narcissist lives in a suspend time and in dispute with the patriarchal society. It arises in the setting a liberal Other who does not prohibit, but rather incites to enjoy. (Finally, love towards the 'Two' and not the 'One' as the exit).

Key-words: new subjectivities; capitalism narcissistic subject; imperative of enjoyment.

\section{Du sous-sol au facebook}

La présentation de cette vignette clinique vise à démontrer que nous vivons une culture du visible, et évaluer dans quelle mesure nous pouvons identifier ses effets sur la construction des subjectivités contemporaines. De la société disciplinaire, place du sujet du conflit, nous passons à une société de surveillance, lieu du sujet narcissique, soumis à l'impératif de jouissance. Le capitalisme est considere comme la cause de la rupture avec la foi dans l'histoire. Casse responsable d'un effonchement de la chaine explicative qui a entouré l'enregistrement des événements publics. Le passé est devenu sans importance et l'avenir entrevu comme troublé et incertain. Le temps est ici et maintenant. Le narcissique vit dans un temps suspendu et en litige avec la société patriarcale. L' Autre liberal apparait sur la scène, qui ne lui interdit pas, mais incite plutôt a jouir. (Enfin, l'amour vers le 'Deux' e non l' 'Un' comme sortie).

Mots-clés: nouvelles subjectivités; capitalisme; sujet narcissique; imperatif de jouissance.

\section{Do porão ao facebook}




\section{Márcia Infante Vieira}

\section{Um caso de erotomania feminino}

A apresentação dessa vinheta clínica visa refletir sobre como estamos vivendo uma 'cultura do visível', e o quanto podemos identificar seus efeitos na construção das subjetividades contemporâneas.

Do porão ao facebook passou a ser um significante no processo analítico de Babi. Mulher de 40 anos, vinda de uma família de origem humilde. Através dos seus estudos conseguiu alcançar grande projeção profissional. A alavanca maior para seu sucesso foi o encontro com o homem que veio a ser seu futuro marido. Segundo Babi, ele Ihe deu o que mais Ihe faltava, ou seja, 'capital social'. Um casal workaholic que, entre estudos e trabalhos, não tinha espaço para filhos. Um dia, uma revelação traz à luz o que se encontrava na sombra, no escuro, escondido no porão. Seu marido fica sabendo ser filho daquela que pensou ser sua irmã. Os dois foram criados como filhos adotivos de um casal; no entanto, o que estava escondido é que a pseudo irmã trabalhava como doméstica na casa do seu pai, com quem teve um caso aos 14 anos de idade. Durante toda a gravidez, essa moça foi mantida escondida no porão da casa e, ao 'dar à luz', o menino foi adotado pelo casal, bem como ela. Babi, muito consternada com essa revelação, decide dar a esse homem um filho, visando que ele passasse a ter uma família de verdade. Após o nascimento da filha, o casal configura um enredo onde o cenário se encontra entre a sombra e a transparência. Esse homem cria um porão a céu aberto. Isola a mulher e as duas filhas, tendo nascido uma segunda 3 anos depois. Nesse isolamento, Babi passa a ser proibida de receber seus familiares em casa, pais e irmãs, bem como frequentar a casa dos mesmos.

A vida social também é enxugada aos limiares desse porão imaginário, embora ele deixasse transparecer relações de sedução com várias outras mulheres. Falava publicamente ao telefone, de forma que Babi escutasse, com mulheres da escola das filhas e do trabalho. Babi, depois de 10 anos trancada nessa ilusão amorosa, num imaginário povoado de ameaças, começa a adoecer e chega a ter glaucoma. Seu corpo traz à luz o real que estava sendo jogado num porão. A saída que encontrou foi, a de em um só golpe, encontrar a chave do porão. Partiu para um jogo de exposição da sua vida privada, para o máximo de luz e visibilidade possíveis. Apaixona-se por um colega de trabalho via um 'olhar' que ele desferiu para ela, que teria penetrado sua alma. Toda essa relação com o pseudo amante se passa na rede social facebook. $\mathrm{O}$ amante virtual, pois nunca tiveram nenhum contato físico, posta músicas, cujas letras, Babi acredita serem todas dirigidas para ela. Ela acata esse fato como realidade inquestionável e passa horas do dia gozando dessa paixão enquanto escuta as músicas. O marido acompanha passo a passo esse romance virtual, na medida em que ela expõe para ele o estado de enamoramento que se encontra, como assume verbalmente tal fato. Esse homem passa a persegui-la e controlá-la dia e noite, sendo o facebook o local através do qual esse controle era exercido, já que o romance era exposto publicamente. A situação do casal se inverte. 
Ela o despreza publicamente e ele passa a querê-la desesperadamente. O marido encontra uma amiga também disposta a brincar de esconde-esconde, ou melhor, de expõe-expõe, e fabricam um perfil falso no "face", tendo como finalidade desmascarar o amante virtual. Ele cai facilmente na armadilha e chega a marcar um encontro com a amiga falsificada. De posse desse desmascaramento, o marido tenta desfazer o romance, mas Babi, irredutível, diz não se importar. O que importa para ela foi o que ele trouxe luz para vida dela, tirou-a do porão, a valorizou, olhou para ela, e, principalmente, a fez sentir desejo sexual, não por ele, mas pelo marido, com quem a vida sexual teve grandes ganhos. E foi por um tropeço do meu inconsciente que Babi começa timidamente bascular do porão ao face começando a alinhavar sua história. Seguidamente, não consigo chamar o amante virtual pelo seu nome, chamando-o de Renato. Re-nato, re-nascido, seu re-nascimento é a função que esse amante ainda tem. Seu escudo diante da sua erotomania em relação ao marido e a repetição da mesma em relação ao amante. Colocamos o pé na estrada, e entre imagens, olhares e tropeços demos início a essa longa caminhada.

\section{Da sociedade disciplinar à sociedade vigiada}

O psicanalista francês, Gérard Wajcman, autor do livro L'Oeil absolu, trabalha sobre um eixo que orienta a sociedade atual: uma organização de hipervigilância sobre seus cidadãos. Submetidos ao olhar de inúmeras câmeras de vigilância, o sujeito contemporâneo tem o seu íntimo, sua zona de sombra e seu recato capturados. A tese do autor é de que "o ver e o ser visto" passaram a ser a base das subjetividades na contemporaneidade. A crença é a de que, através de uma transparência total, o sujeito possa alcançar sua verdadeira essência. Para isso, a luminosidade é lançada sob os recantos do eu mais sombrio, deixando o sujeito sem a possibilidade de se esconder. Wajcman denuncia que a sociedade avançou de uma organização disciplinar, para uma organização de vigilância, onde um OLHO, um grande OLHO controlador e absoluto, passou a vigiar a todos. Como efeito dessa hipervigilância surge uma sociedade do suspense e da suspeita. O sujeito está colocado num lugar de eterno suspeito de um crime que ainda não cometeu, mas que cometerá. Um sentimento inconsciente de culpa passa a ser reforçado, já que os dispositivos de controle desse OLHO, onividente, tomam toda a cidade em seus espaços públicos e privados. Como outro lado da mesma moeda, o prazer de estar sendo visto aparece nas estatísticas das pesquisas do autor, onde as câmeras parecem estimular comportamentos exibicionistas. Lendo psicanaliticamente tais resultados, Wajcman analisa que os sujeitos da modernidade, diante da exposição, viviam desconforto e mal-estar, e faziam sintomas. Em outras palavras, eram sujeitos que apresentavam, como saída, sintomas neuróticos. Em contrapartida, os sujeitos da contemporaneidade, sujeitos narcisistas, vivem satisfação, ou seja, gozam ao se expor.

Podemos inferir que ambas as respostas são saídas para um circuito pulsional, onde a pulsão escópica é o que está em jogo. Ficam as questões: o que teria ocorrido nesse circuito que tenha 
impactado e alterado as subjetividades e os laços sociais? Vítimas ou protagonistas? Iludidos e ingênuos ou sujeitos arraigados num imperativo de gozo, incapazes de fazerem renúncias e adiamentos? Ativos ou passivos?

Jacques Lacan (1964), em seu Seminário 11, ao falar do circuito pulsional, afirma que para Freud, esses termos atividade e passividade no nível da pulsão, foram utilizados meramente num sentido gramatical. Na verdade, sua intenção teria sido mostrar o movimento de vai-e-vem do circuito pulsional. Um abre e fecha contínuo e inesgotável. Faz uma graça, quando exemplifica que o masoquista, mesmo na sua fase passiva, "trabalha como um burro" (LACAN, 1962, p.189). Sendo assim, onde existe o ver, existe o ser visto. Quer dizer, não existe uma complementariedade por oposição dessas duas posições. O "se mostrar", o "se exibir", alimentam a sociedade vigilante encarnando o outro lado da mesma moeda.

\section{Capitalismo e narcisismo}

Christopher Lasch, em seu livro A Cultura do Narcisismo (1983), dá a partida para o estudo das relações entre crise do capitalismo na sociedade ocidental e subjetividade. $O$ autor acredita que, diante da falência das ciências que sustentavam o liberalismo, nada surgiu em suplência. Aponta para a ocorrência de uma ruptura com a fé na história, ruptura responsável por um colapso na cadeia explicativa que cercava o registro dos eventos públicos. O passado tornou-se irrelevante e o futuro vislumbrado como conturbado e incerto.

A desconfiança nos governantes gerou um auto-governo, onde a lógica individualista exacerbou uma guerra de tudo contra tudo. $\mathrm{O}$ eu é elevado à categoria de bem supremo e os cuidados de si passam a ser a garantia de felicidade. Para alcançar esse êxito tornou-se necessário a libertação das condições repressoras do passado. Os fundamentos da família burguesa foram destruídos através das críticas radicais feitas ao autoritarismo do patriarcado, à moralidade sexual repressora, à censura literária e à ética do trabalho. Como produto final do individualismo, o homem econômico deu lugar ao homem psicológico. A culpa deu lugar à angústia. Esse homem, liberado das amarras da repressão passada, passa a viver a sexualidade de forma mais permissiva, mas, apesar disso, não encontra a paz sexual. Seu lema é que seus desejos não tenham limites, o tempo é o aqui e agora e, a exigência é de um gozo eterno. O resultado dessa equação é o surgimento de um homem que vive em estado de desejo, desassossegado e constantemente insatisfeito.

O narcisista não se interessa pelo futuro, na medida em que não tem interesse pelo passado, pois o considera nostálgico. Vive em um tempo suspenso e, por isso, porta uma pobreza psíquica, oriunda da incapacidade de avaliar suas experiências. Surgem os especialistas visando tratar um dos sintomas mais importantes dessa crise na cultura, ou seja, a indiferença com o passado. 0 autocrescimento psíquico ganha importância em detrimento de um enfraquecimento do sentido de tempo histórico. Autenticidade e consciência tornaram-se pilares do eu e das novas estratégias de viver o momento e de viver para si. O eu ganha o centro da sobrevivência individual, desbancando 
o sentido histórico e geracional. O clima terapêutico substitui o clima religioso, visando o bem-estar pessoal, a saúde e segurança psíquica. Para o homem narcísico, o mundo é um espelho que reflete seu eu grandioso. Seu interesse confina-se àqueles que estão em estreita proximidade consigo mesmo.

Esse momento histórico tem como característica a declaração de litígio a todas as formas de autoridade patriarcal. Condenou-se o superego, o que veio enfraquecer o superego social, representado pelos pais, professores e pregadores. No contrafluxo das expectativas, o declínio da autoridade institucionalizada não deu lugar à um declínio do superego nos indivíduos. Contrariamente, há o encorajamento do desenvolvimento de um superego, que por ser mais arcaico, ordena que se goze.

A terapia encontra seu lugar dando conta do homem psicológico do século $\mathrm{XX}$, perseguido que este é pela ansiedade, depressão e pelo sentimento de vazio. $O$ amor é acenado como uma via possível para se alcançar o bem-estar e a saúde mental, porém, o sentido desse amor é dado pelo preenchimento das necessidades individuais, abolindo-se qualquer submissão opressiva do outro. Sendo assim, a saúde mental passou a significar "a destruição de inibições e a imediata gratificação de qualquer impulso" (Lasch, 1983, p. 34). A auto-confissão e o exibicionismo vieram sustentar essa terapêutica, pois falando de si, de seus merecimentos e de suas razões, o narcisista encontra o álibi para "desviar-se da crítica e de negar as responsabilidades por seus atos" (Lasch, 1983, p. 34).

O vazio interior, oriundo dessa busca desenfreada e inalcançável pela felicidade e pelo gozo absoluto, desemboca em angústia. Ficou mais difícil aceitar a banalidade da existência cotidiana, o que fez com que a fama ganhasse valor de autoestima. As pessoas ficaram imersas numa impossibilidade de lidar com o fracasso e a perda. O mundo público passou a ser visto como um espelhamento do eu, tendo sido rompidas as barreiras entre o público e o privado e, consequentemente, a barreira do pudor. Amizades, casamentos e casos de amor encontraram dificuldades em se sustentarem na sociedade contemporânea, pois as relações perderam a função de proporcionar alívio, assumindo um caráter de hostilidade e combate.

\section{Lugar do outro na contemporaneidade}

A proposta individualista coloca o homem contemporâneo "mais exposto à deriva da pulsão" (Coelho dos Santos, 2001, p. 302). Na sociedade moderna ocidental, os sintomas neuróticos eram coletivos por estarem referidos ao Nome-do-Pai. Atualmente, a ruptura com as tradições fez fraquejar o lugar do Outro, o que dificultou o encontro com "algo que possa ser dito coletivo" (Coelho dos Santos, 2001, p. 303). Lacan retoma Freud estudando a psicose. Essa eleição tem em seu bojo o declínio da importância do pai como agente da castração. As neuroses, edificadas no complexo de Édipo, valoram simbolicamente a figura do pai, já que o pai está morto.

Nesse contexto, quem não simboliza a falta, o não-sentido, o mal-entendido, por meio do Nome-do-Pai, é psicótico, está fora do discurso e do laço social dominante. Esse foi o raciocínio que 
conduziu o primeiro retorno de Lacan a Freud e embasou toda sua primeira clínica. (Coelho dos Santos, 2001, p. 305).

No segundo momento de sua clínica, Lacan, ainda baseado em Freud, postula que a posição psicótica é dominante na cultura, uma vez que, a exclusão do Nome-do-Pai, isto é, o não recalcamento da figura paterna, tornaram-se coletivos. A cultura passa a ter a psicose como estrutura.

Considerando que a função paterna, como agente da castração, baliza a ordenação do sujeito diante do falo, conclui-se que mexer nessa equação, inevitavelmente, produzirá como efeito, novos sintomas. O sujeito estrutura-se no campo do desejo ordenado pela castração, o que o coloca em uma posição subjetiva diante do falo, ou seja, diante da diferença dos sexos e das gerações. Com o avanço da humanidade decorrentes das revoluções industrial, científica e sexual, a sociedade construída sobre o eixo patriarcal se desequilibrou, o que trouxe uma desconstrução nos papeis dos homens e mulheres no que se refere à parceria amorosa.

Surge no cenário um Outro liberal. Nada mais se proíbe, todos podem tudo e, ninguém mais diz não. A partir de então, sob que referencias se estrutura o sujeito contemporâneo? Nessa sociedade de hoje, o Outro não proíbe, e sim, incita a gozar.

Ao que se refere as parcerias amorosas, trabalho com a hipótese de que a revolução sexual conduziu a um ideal de equivalência entre os sexos, normalizando o gozo a partir do referencial masculino. Isso se evidencia através do poder aquisitivo conquistado pelas mulheres, que se equivale ao gozo fálico masculino.

Na estruturação subjetiva ordenada pelo complexo de Édipo, um sexo tem para o outro um efeito de castração, por encarnar a impossibilidade da completude, do gozo absoluto. O capitalismo, com seu discurso do tudo ser possível, rompeu com essa regra fundamental. Na atualidade, homens e mulheres buscam em seus parceiros um outro que possua todas as características de um produto perfeito, aquele que reúna as virtudes do masculino e do feminino. Na medida em que essa tarefa é impossível, a insatisfação torna-se a mola propulsora que deflagra buscas incessantes, onde o outro, congelado na categoria de objeto, é considerado descartável por não propiciar o gozo absoluto.

\section{De volta à Babi}

Babi me parece uma representante do sujeito contemporâneo, na medida em que o excesso de visibilidade se apresenta. Rompe, sem pudor, as barreiras do íntimo, do recato e do pudor. Goza por se expor, e goza por expor aquele que identifica como seu algoz, seu marido. Quanto mais seu caso virtual torna-se público, mais ela goza. Não se acredita aparelhada para viver a falta de ordem alguma, pois uma vez que seu projeto erotômano fracassou, quando seu corpo doente the fez ver que sua anulação não lhe garantiu o amor e fidelidade do marido, ela tampona a falta suturando-a com um novo arranjo amoroso. Esse novo arranjo é colorido com as tonalidades do contemporâneo, 
já que a cena é vivida no facebook. A análise começou a operar uma transformação no jorro de gozo de Babi. Tanto pedia para ser escutada e vista, que essa experiência, nada virtual, permitiu que ela começasse a ouvir e ver. Vem enxugando seu gozo passo a passo, o que teve como efeito uma tímida amarração, onde surge como protagonista da sua história e de seus enredos. Pouco velamento existe entre o casal, pois acreditam que serem leal um com o outro significa se devassarem. Apesar disso, uma membrana porosa parece começar a envolver Babi dando-lhe um esboço de contorno de si.

\section{O amor como saída}

Alain Badiou, no seu livro Elogio ao Amor (2009), responde às questões levantadas por Nicolas Truong, onde desenvolve suas ideias sobre a ameaça que o amor sofre na atualidade, destituído da sua potência de acontecimento incomensurável. O filósofo francês não considera 0 amor como um contrato feito por dois narcisistas, e sim, um trabalho de reinvenção constante.

Sim, de fato acredito que liberal e libertário convergem para a ideia de que o amor é um risco inútil. E que podemos ter, de um lado, uma espécie de conjugabilidade planejada, que se estenderá no bem-estar do consumo e, de outro, arranjos sexuais agradáveis e repletos de prazer que dispensam a paixão. Por esse ângulo, penso que o amor, no mundo tal como ele é, acaba sofrendo essa pressão, esse cerceamento e, nesse sentido está ameaçado. E acredito que defendelo seja uma tarefa filosófica, entre outras (Badiou, 2013, p. 13-14).

Segundo Badiou, o amor é uma experiência que transcende a singularidade, indo ao encontro do universal. Partindo da diferença que o amor possibilita, existe uma redução do si, da identidade, que faz valer os riscos, provas e sofrimentos. Nessa concepção, através do amor, o mundo pode ser experimentado pela diferença.

O filósofo considera Lacan um dos maiores teóricos do amor. Sua afirmação de que 'não existe relação sexual' causou escândalo em uma época em que todos falavam mais e mais sobre relações sexuais. Badiou a interpreta assim:

Lacan nos lembra que na sexualidade cada um está, na verdade, preocupado com sua própria história, digamos assim. Há, é claro, a mediação do corpo do outro, mas, no fim das contas, o gozo será sempre o nosso próprio gozo. O sexual não une, separa. Uma pessoa estar nua, colada a outra, é uma imagem, uma representação imaginária. A realidade é que o gozo nos conduz para longe do outro. A realidade é narcisista, o vínculo é imaginário. (Badiou, 2013, p. 18-19)

Seguindo a trilha dessas reflexões, o amor encontra seu lugar como suplente dessa inexistente relação sexual. Pela via do amor, Lacan acredita que o sujeito vai além de si, além do narcisismo. No sexo, o outro media o alcance do gozo, enquanto que no amor, a mediação do outro 
passa a ter valor em si. "Enquanto o desejo se dirige no outro, de modo sempre um tanto fetichista, a objetos de eleição _ como os seios, as nádegas, o pênis_o amor se dirige ao próprio ser do outro" (Badiou, 2013, p. 19-20).

Badiou sublinha que a construção do mundo, a partir de uma diferença, é algo muito distinto da experiência da diferença. Recusa a ideia religiosa de que a experiência da alteridade se fundamenta na ética, pois não vê nada de ético no amor como tal. Postula uma proposta existencial: "construir um mundo de um ponto de vista descentrado em relação à minha mera pulsão de sobrevivência ou de meu interesse bem compreendido" (BADIOU, 2013, p.21). Para ele, todo amor inicia-se em um encontro e sua potência advém de ser um encontro entre duas diferenças e, por isso, é um evento. Esse evento é uma experiência do mundo, construído a partir do prisma de Dois e, não mais do Um. Nomeia essa experiência como "Cena do Dois", na qual se constrói um determinado tipo de verdade, a verdade sobre o Dois, a verdade da diferença como tal. Esta aí o caráter universal do amor, sua proposta de ser uma nova experiência de verdade sobre o que é ser Dois, e não Um.

O acaso do encontro é fixado no compromisso, onde localiza-se a verdadeira fidelidade de um vínculo amoroso, uma vez que a eternidade é anunciada. A questão que se coloca é como depois os amantes inserem essa eternidade no tempo. Badiou responde colocando uma interrogação:

Mas que eternidade pode existir no próprio tempo da vida? É isso que o amor, cuja essência é a fidelidade no sentido que dou a essa palavra, vem provar. Em suma, a felicidade! Sim, a felicidade amorosa é a prova de que o tempo pode acolher a eternidade. Outras provas disso são o entusiasmo político quando participamos de uma ação revolucionária, o prazer que nos propiciam as obras de arte e a alegria quase sobrenatural que sentimos ao compreender enfim uma teoria científica a fundo. (Badiou, 2013, p. 34)

\section{Considerações finais}

Na contemporaneidade, a proposta de Badiou tem um cunho revolucionário, pois caminha no contrafluxo de uma sociedade culturalmente narcisista, onde o homem encontra-se em suspenso, rompido com o passado e com o Outro que o castra. Sobrevivente do aqui e agora, ao mesmo tempo réu e vilão de seu destino, o homem psicológico encontra-se congelado no presente e descompromissado com o outro enquanto sujeito. Amar, dentro dessa cartografia das subjetividades atuais, dentro dos novos sintomas parece uma proposta de temporalização e de espacialização, onde a alteridade pode encontrar um lugar diante das mudanças operadas na cultura.

\section{Referências Bibliográficas}

Badiou, A.; TROUNG, N. (2013). Elogio ao Amor. São Paulo: Martins Fontes. 
Coelho dos Santos, T. (2001). Quem Precisa de Análise Hoje? O discurso analítico: novos sintomas e novos laços sociais. Rio de Janeiro: Bertrand.

Lacan, J. (1985). O seminário, livro 11: os quatros conceitos fundamentais da psicanálise. Rio de Janeiro: Zahar.

Wajcman, G. (2011). L'OEIL absolu. Paris: Denoel.

Citacão/Citation: Vieira, M. I. (mai. a out. 2015). Do porão ao facebook. Revista aSEPHallus de Orientação Lacaniana, 10(20), 61-69. Disponível em www.isepol.com/asephallus. doi: 10.17852/1809709x.2019v10n20p61-69

Editor do artigo: Tania Coelho dos Santos.

Recebido/Received: 24/06/2015 / 06/24/2015.

Aceito/Accepted: $18 / 07 / 2015$ / 07/18/2015.

Copyright: (C) 2013 Associação Núcleo Sephora de Pesquisa sobre o moderno e o contemporâneo. Este é um artigo de livre acesso, que permite uso irrestrito, distribuição e reprodução em qualquer meio, desde que o autor e a fonte sejam citados/This is an open-access article, which permits unrestricted use, distribution, and reproduction in any medium, provided the author and source are credited. 